\title{
Calcium Transients in the Rhabdomeres of Dark- and Light- Adapted Fly Photoreceptor Cells
}

\author{
Johannes Oberwinkler and Doekele G. Stavenga \\ Department of Neurobiophysics, University of Groningen, NL-9747 AG Groningen, The Netherlands
}

The light response of fly photoreceptor cells is modulated by changes in free $\mathrm{Ca}^{2+}$ concentration. Fly phototransduction and most processes regulating it take place in or very close to the rhabdomere. We therefore measured the kinetics and the absolute values of the free $\mathrm{Ca}^{2+}$ concentration in the rhabdomere of fly photoreceptor cells in vivo by making use of the natural optics of the fly's eye. We show that $\mathrm{Ca}^{2+}$ flowing into the rhabdomere after light stimulation of dark-adapted cells causes fast $\mathrm{Ca}^{2+}$ transients that reach peak values higher than $200 \mu \mathrm{M}$ in $<20 \mathrm{msec}$. Approximately $500 \mathrm{msec}$ later, the free $\mathrm{Ca}^{2+}$ concentration has declined again to $\sim 20 \mu \mathrm{m}$. The duration of the $\mathrm{Ca}^{2+}$ transients becomes still shorter, and their size reduced, when the photoreceptor cell is light-adapted. This reduction in duration and size of the $\mathrm{Ca}^{2+}$ transients is graded with the intensity of the adapting light. The kinetics and absolute values of the free calcium concentration found to occur in the rhabdomere are suitable to mediate the fast feedback signals known to act on the fly phototransduction cascade.

Key words: phototransduction; light adaptation; $\mathrm{Ca}^{2+}$ transients; local $\mathrm{Ca}^{2+}$ signaling; $\mathrm{Ca}^{2+}$ feedback; fluorescent $\mathrm{Ca}^{2+}$ indicators
Fly photoreceptor cells are the prototypical model system for the phospholipase C (PLC)-mediated activation of ion channels encoded by members of the trp gene family (Hardie and Minke, 1995). In fly photoreceptors, these channels are highly permeable for $\mathrm{Ca}^{2+}$ (Hardie and Minke, 1992; Reuss et al., 1997) and exclusively found in the rhabdomeres (Ranganathan et al., 1994; Huber et al., 1996a; Niemeyer et al., 1996). The rhabdomere consists of microvilli, tube-like protrusions of the plasma membrane (for review, see Hardie, 1985), which contain most known molecules of the transduction cascade as well as many molecules involved in the regulatory control of the cascade (for review, see Montell, 1998).

Invertebrate photoreceptor cells can adjust their sensitivity to the average light level they encounter, i.e., they show pronounced light adaptation (for review, see Laughlin, 1989). Light adaptation comprises many different processes and crucially depends on an increase of intracellular $\mathrm{Ca}^{2+}$ concentration (Lisman and Brown, 1975; Bader et al., 1976; Muijser, 1979). Recent studies have started to unravel the mechanisms by which $\mathrm{Ca}^{2+}$ exerts its regulatory action. $\mathrm{Ca}^{2+}$ has been proposed to act directly on the light-activated channels (Hardie and Minke, 1994; Hardie, 1995; Obukhov et al., 1998), or via binding to calmodulin that interacts with the light-activated channels (Phillips et al., 1992: Warr and Kelly, 1996; Scott et al., 1997). Additionally, a $\mathrm{Ca}^{2+}$-regulated PKC (Huber et al., 1998) is crucial for $\mathrm{Ca}^{2+}$-dependent deactivation of the light response (Ranganathan et al., 1991) and light adaptation (Hardie et al., 1993). Other important molecules in the phototransduction cascade that have been suggested to be modulated by $\mathrm{Ca}^{2+}$ or by $\mathrm{Ca}^{2+} /$ calmodulin include neitherinactivation-nor-afterpotential C (Porter et al., 1993), inactivation-

\footnotetext{
Received Sept. 9, 1999; revised Nov. 15, 1999; accepted Dec. 22, 1999.

We thank J. Land and H. L. Leertouwer for expert technical assistance.

Correspondence should be addressed to J. Oberwinkler, Department of Neurobiophysics, University of Groningen, Nijenborgh 4, NL-9747 AG Groningen, The Netherlands. E-mail: j.oberwinkler@phys.rug.nl.

Copyright (C) 2000 Society for Neuroscience 0270-6474/00/201701-09\$15.00/0
}

nor-afterpotential D (Chevesich et al., 1997), and PLC (Running Deer et al., 1995). Together these findings suggest that $\mathrm{Ca}^{2+}$ plays a central role in the regulation of the light response. However, it is poorly understood how the different $\mathrm{Ca}^{2+}$-dependent processes interact. A key element missing for a more rigorous understanding of $\mathrm{Ca}^{2+}$-mediated regulation of phototransduction is the knowledge of the magnitude and the time course of the free $\mathrm{Ca}^{2+}$ concentration in the rhabdomere $\left(\left[\mathrm{Ca}^{2+}\right]_{\mathrm{rh}}\right)$.

Previous studies have shown that light stimulation causes a rapid rise in free $\mathrm{Ca}^{2+}$ concentration throughout the photoreceptor cell that can exceed $10 \mu \mathrm{M}$ (Hardie, 1996a; Oberwinkler and Stavenga, 1998). The anatomy of the rhabdomere, however, suggests that the kinetics and absolute values of $\left[\mathrm{Ca}^{2+}\right]_{\mathrm{rh}}$ might be considerably different from those encountered in the cell body. Indeed, Postma et al. (1999) have found in a modeling study that the free $\mathrm{Ca}^{2+}$ concentration might rise to millimolar values in the microvilli after the absorption of a single photon. In this study we describe a method to quantitatively measure $\left[\mathrm{Ca}^{2+}\right]_{\mathrm{rh}}$ in vivo. We show that illumination of dark-adapted photoreceptor cells increases $\left[\mathrm{Ca}^{2+}\right]_{\mathrm{rh}}$ to values possibly as high as $600 \mu \mathrm{M}$, whereas light adaptation reduces the peak amplitude of the $\mathrm{Ca}^{2+}$ signal.

\section{MATERIALS AND METHODS}

All experiments were performed on female blowflies (Calliphora vicina). These large flies allow long-lasting and stable intracellular recordings of photoreceptor cells with intracellular electrodes that are blunt enough for iontophoretic injection of fluorescent $\mathrm{Ca}^{2+}$ indicators (see below), which might be difficult in Drosophila. Many genes of molecules involved in the phototransduction or in its regulation have been cloned in Calliphora and are found to be $\sim 80 \%$ homologous to corresponding genes of Drosophila (Huber et al., 1996a,b, 1998). This indicates that the results obtained in Calliphora will be of direct relevance to the interpretation of data from Drosophila. Either wild-type or white-eyed mutant chalky flies were used. The chalky flies were obtained from a laboratory culture, whereas the wild-type flies were from $\mathrm{F} 1$ generations raised from animals caught in Groningen (The Netherlands).

Preparation and the electrophysiological methods were as described by Oberwinkler and Stavenga (1998). Briefly, the animal was immobilized 
and placed on the stage of a Leitz Orthoplan epifluorescence microscope (Leitz, Wetzlar, Germany). The photoreceptor cells were impaled with borosilicate glass electrodes $(1.0 \mathrm{~mm}$ outer diameter, $0.58 \mathrm{~mm}$ inner diameter; Clark Electromedical Instruments, Reading, UK) pulled on a P-97 electrode puller (Flaming-Brown; Sutter Instruments, Novato, CA). Electrodes were filled with a $0.1 \mathrm{M} \mathrm{KCl}$ solution containing $5 \mathrm{~mm}$ of the $\mathrm{Ca}^{2+}$ indicator dyes Oregon Green 1 (OG1), Oregon Green 5N (OG5N), or Fluo5N (Molecular Probes, Eugene, OR), yielding resistances between 150 and $250 \mathrm{M} \Omega$ in the tissue. The $\mathrm{Ca}^{2+}$ indicator dyes were injected into the cell by applying $0.5-1 \mathrm{nA}$ negative current pulses of 1 sec duration in a $0.5 \mathrm{~Hz}$ duty cycle for $\sim 1 \mathrm{~min}$. An Axoclamp 2A amplifier (Axon Instruments, Foster City, CA) was used for all electrophysiological experiments. After capacity compensation, the electrodes could be used in the switched current-clamp mode (DCC mode) with switching frequencies typically exceeding $3 \mathrm{kHz}$, indicating that the time constant of the electrode did not limit the frequency range of the membrane potential measurements. All measurements of the membrane potential presented, however, have been done in the nonswitching "bridge" mode.

In experiments where we aimed to simultaneously record the fluorescence and the membrane potential of the photoreceptor cell, it was essential to record from a photoreceptor cell that had its direction of view very well aligned (within $2^{\circ}$ ) with the optical axis of the microscope. We therefore took care to place the animal on the microscope stage in such a way as to insure that the electrode would follow a path crossing the region of the deep pseudopupil (Franceschini and Kirschfeld, 1971). The electrode was subsequently advanced into the region of the deep pseudopupil, and a photoreceptor cell was impaled there. When we only wanted to record the fluorescence from the $\mathrm{Ca}^{2+}$ indicator dye, the electrode was withdrawn after dye-filling the cell. The animal was then aligned under visual control to yield the maximum fluorescence from the dye-filled cell.

The blue-induced green fluorescence of the $\mathrm{Ca}^{2+}$ indicator dye was measured with a photomultiplier (R928; Hamamatsu, Bridgewater, NJ) that was shielded with a pinhole of $0.2 \mathrm{~mm}$ diameter to reduce background from the autofluorescence of the eyes. Light from a $75 \mathrm{~W}$ Xenon arc lamp was focused through a fast shutter (L2, Uniblitz; Vincent Associates, Rochester, NY), then passed through a $510 \mathrm{~nm}$ fluorescence cube and was subsequently focused with an objective onto the specimen. Either a $10 \times$ [numerical aperture (NA), 0.25; Spindler and Hoyer, Göttingen, Germany] or a Luminar objective $(f=25 \mathrm{~mm}$; Zeiss, Oberkochen, Germany) with variable numerical aperture (NA 0.031$0.15)$ were used.

The signals from the photomultiplier and the electrode amplifier were low-pass filtered at 2 or $4 \mathrm{kHz}$ before being sampled at 5 or $10 \mathrm{kHz}$, respectively. Data analysis was performed off-line; all recordings shown represent averages of the same experiment repeated 6-40 times. We always checked that the waveform of the recorded traces did not considerably change during the experiment. Usually however, the fluorescence signal decreased throughout the experiment; whether this represents bleaching or removal of the dye from the cytosol is not known. In some cases, the fluorescence traces and calculated free $\mathrm{Ca}^{2+}$ concentrations have been smoothed by averaging 10 consecutive values (always representing $1 \mathrm{msec}$ ). To calculate the free $\mathrm{Ca}^{2+}$ concentration from the fluorescence traces, the minimum and maximum fluorescence levels were determined as outlined in Results, and the free $\mathrm{Ca}^{2+}$ concentration was calculated as: $\left[\mathrm{Ca}^{2+}\right]_{\mathrm{rh}}=K_{\mathrm{d}} *\left(F-F_{\min }\right) /\left(F_{\max }-F\right)$ (Grynkiewicz et al., 1985). The $K_{\mathrm{d}}$ value for OG5N was assumed to be $20 \mu \mathrm{M}$ (Haugland, 1996). In all calculations we hence assume that the characteristic curve of $\mathrm{Ca}^{2+}$ binding to the indicator has a Hill coefficient of 1 . Importantly, the direct measurement of $F_{\max }$ and $F_{\min }$, as outlined in Results, both include the background fluorescence, which was found to be constant over the time-scale of our experiments, as much as the signal $F$. Additional background subtraction is therefore not necessary.

\section{RESULTS}

\section{Recording $\mathrm{Ca}^{2+}$-induced fluorescence from the rhabdomere of fly photoreceptor cells}

We have recently demonstrated that the free $\mathrm{Ca}^{2+}$ concentration can be measured by recording the fluorescence emitted from $\mathrm{Ca}^{2+}$ indicator dyes in single photoreceptor cells of blowflies in vivo (Oberwinkler and Stavenga, 1998). In these earlier measurements, the fluorescent signal was sampled from the entire cell.

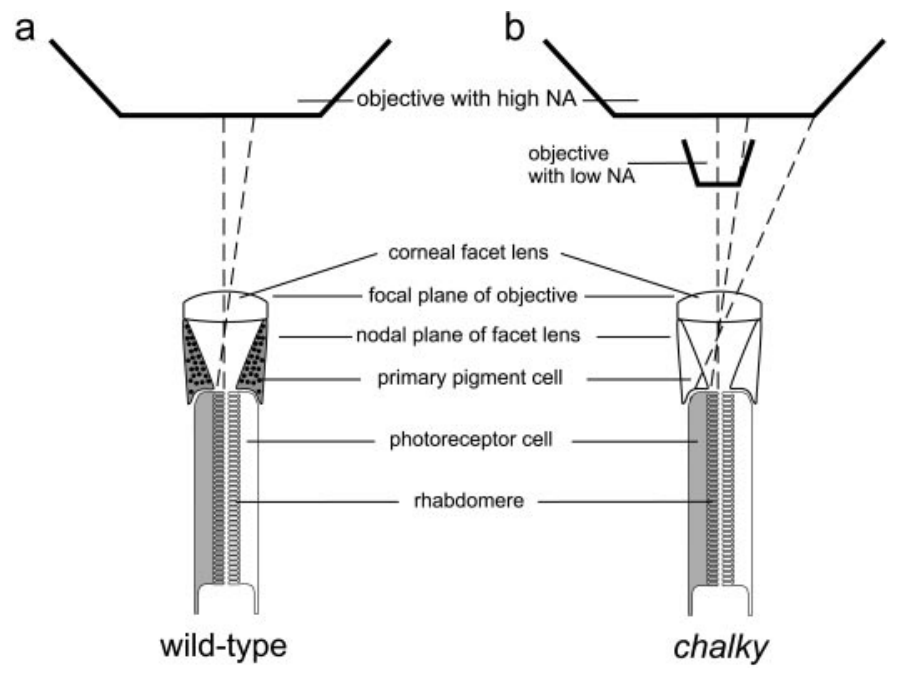

Figure 1. Method for recording $\mathrm{Ca}^{2+}$-induced fluorescence only from the rhabdomere of fly photoreceptor cells. Light leaving the rhabdomere is focused by the corneal facet lens to form a beam that diverges by $1-2^{\circ}$ (van Hateren, 1984), whereas the light originating from the other parts of the photoreceptor cell leaves the eye under a wider angle $\left(10^{\circ}\right.$, Oberwinkler and Stavenga, 1998). In wild-type flies, the screening pigments in the primary pigment cells (indicated by the dark dots and the shading in the primary pigment cells) absorb the light coming from parts of the cell other than the rhabdomere. Therefore, only light originating from the rhabdomeres can leave the eye through its natural optics $(a)$. When using chalky flies, the same optical principle can be exploited. Because the primary pigment cells no longer contain pigment granules (indicated by the empty primary pigment cells), it is necessary to reduce the NA of the objective to preferentially sample the light coming from the rhabdomere and to reject the light coming from other parts of the cell $(b)$.

Because $\mathrm{Ca}^{2+}$ influx in fly photoreceptor cells is a highly localized process, only occurring in the rhabdomere (Ranganathan et al., 1994; Huber et al., 1996a; Niemeyer et al., 1996), averaging the $\mathrm{Ca}^{2+}$-induced fluorescence across the entire cell might have obscured important kinetic details. We reasoned that it should be possible to record exclusively the fluorescence emanating from the rhabdomere by making use of the natural optics of the fly's eye, because the rhabdomere samples light only from a narrow angle of view, which in blowflies amounts to $1-2^{\circ}$ (van Hateren, 1984). In fact, in wild-type flies, light that hits a facet lens under an angle exceeding $1-2^{\circ}$ is absorbed by the dense pigmentation in the primary pigment cells. Light emitted from fluorophores in the rhabdomeres follows the reverse path and is consequently focused by the ommatidial lenses to form a beam with $1-2^{\circ}$ divergence. Light originating from other parts of the cell would pass through the facet lenses forming a much wider beam of $\sim 10^{\circ}$ (Oberwinkler and Stavenga, 1998). This light, however, is to a very large extent absorbed by the pigment granules in the primary pigment cells (Fig. 1a), allowing only the light emanating from the rhabdomere to leave the eye.

In Figure 2 the fluorescence signal from the $\mathrm{Ca}^{2+}$ indicator dye OG5N ionotophoretically injected in a photoreceptor cell of a wild-type fly is shown on three different time scales. The recordings show that, when the bright light is turned on, the fluorescence stays at a low initial level for $\sim 6 \mathrm{msec}$ before a pronounced increase is observed (Fig. 2a). This initial level of fluorescence is caused by the autofluorescence of the retina and the fluorescence of the OG5N indicator dye at the low $\mathrm{Ca}^{2+}$ levels found in resting photoreceptor cells $(0.16 \mu \mathrm{M}$; Hardie, 1996a). From this initial level, the fluorescence increases rapidly to reach its maximum 


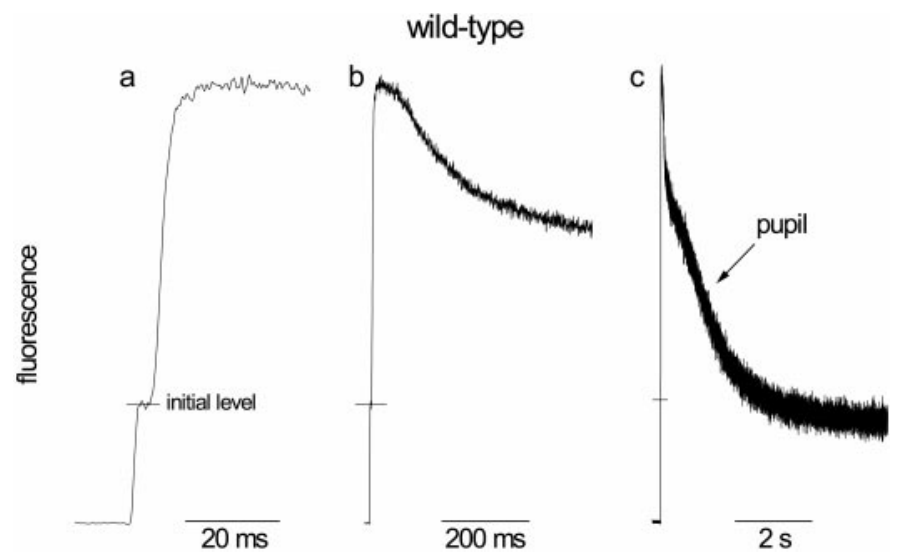

Figure 2. Fluorescence signal recorded from a photoreceptor cell of a wild-type fly with the $\mathrm{Ca}^{2+}$ indicator dye OG5N on three different time scales. When the light is turned on, the fluorescence signal stays at the initial level (indicated by the small horizontal lines) for $\sim 5 \mathrm{msec}$, before a measurable increase in the free $\mathrm{Ca}^{2+}$ concentration is observed $(a)$. The initial level of fluorescence is caused by the autofluorescence of the tissue and the fluorescence of the $\mathrm{Ca}^{2+}$ indicator dye at low $\mathrm{Ca}^{2+}$ concentrations. The fluorescence signal shows an initial plateau at its maximum value $(a, b)$, from which it decreases to $\sim 50 \%$ (calculated between the initial level and the peak) during the first $500 \mathrm{msec}$ of light stimulation $(b)$. Wild-type flies possess a powerful pupil mechanism (Kirschfeld and Franceschini, 1969) that efficiently reduces the fluorescence from the rhabdomere (Stavenga, 1983). This pupil mechanism cuts in after $\sim 500$ $\operatorname{msec}(c$, arrow).

$\sim 20$ msec after the beginning of the light stimulation. The fluorescence stays for a short period at this maximum level before it decreases to reach a level of $\sim 50 \%, 500 \mathrm{msec}$ after the peak (Fig. $2 b$ ). For still longer periods of illumination, the fluorescence decreases strongly to values below the initial level (Fig. 2c, arrow). This decrease is attributable to the pupil mechanism (Kirschfeld and Franceschini, 1969) present in wild-type flies that is known to drastically reduce the fluorescence emanating from the rhabdomere (Stavenga, 1983).

The pupil mechanism, albeit serving an important function for the fly's vision (Howard et al., 1987), makes it impossible to quantitatively analyze the fluorescence signals of dark-adapted photoreceptors stimulated for $>500 \mathrm{msec}$; the same problem occurs when light-adapted photoreceptors are to be studied (see below). To avoid the problems arising from the pupil mechanism, we devised a way to record the fluorescence from the rhabdomeres of white-eyed chalky flies that lack the pupil mechanism. However, in these mutants also the pigment granules in the primary pigment cells are missing, allowing the fluorescence from the cell soma to leave the eye. We therefore narrowed the NA of the objective and thereby the angle of the measured light beam. According to the optical situation outlined above, this isolates the signal from the rhabdomere and rejects light coming from other parts of the cell (Fig. $1 b$ ).

In Figure 3 the results of an experiment with the $\mathrm{Ca}^{2+}$ indicator dye OG5N injected in a chalky photoreceptor cell are shown. In the top panels (Fig. $3 a-c$ ), the fluorescence is recorded with a NA of 0.15 , i.e., an acceptance angle $\alpha=8.1^{\circ}$; in the other panels the NA was reduced to $0.065\left(\alpha=3.7^{\circ}\right.$; Fig. $\left.3 d-f\right)$, and to $0.039\left(\alpha=2.2^{\circ}\right.$; Fig. $\left.3 g-i\right)$. All traces are normalized to the initial level to facilitate comparison of the size of the signal. The striking difference between the different recording situations is the increased size of the initial transient when the NA is reduced. Additionally, the rising and falling flanks of the initial fluores- cence transient are steeper in recordings with reduced NA (Fig. $3 a$ vs Fig. $3 g$ for the rising flank; Fig. $3 b$ vs Fig. $3 h$ for the falling flank). This indicates that the $\mathrm{Ca}^{2+}$ increase in the rhabdomere is faster and reaches much higher concentrations than the $\mathrm{Ca}^{2+}$ increase in the rest of the cell. Importantly, recordings from dark-adapted chalky flies made with low NAs (Fig. $3 g-i$ ) are essentially identical to the recordings from wild-type flies for the first $500 \mathrm{msec}$ (Fig. 2a,b), showing that the rhabdomeral fluorescence signal in chalky mutants can be isolated with comparable quality as in wild-type flies. Photoreceptor cells of chalky mutants, however, need to be very well aligned to match the reduced NA of the objective; imperfect alignment results in reduced signal amplitudes and increased noisiness compared to recordings from wild-type flies.

These experiments clearly demonstrate that it is possible to measure the fluorescence from the rhabdomeres in vivo in both wild-type flies and chalky mutants. They show the distinct size and kinetics of the free $\mathrm{Ca}^{2+}$ concentration in the rhabdomere as compared to the rest of the cell body. Recordings with larger NAs in chalky therefore integrate over different compartments of the photoreceptor cells with largely different $\mathrm{Ca}^{2+}$ kinetics.

\section{The size of the initial $\mathrm{Ca}^{2+}$ transient in the rhabdomere exceeds $200 \mu \mathrm{M}$}

The $\mathrm{Ca}^{2+}$-induced fluorescence measured with OG5N rises very fast to a plateau that is maintained for $\sim 30-50 \mathrm{msec}$ before the fluorescence declines again (Figs. $2 a, b, 3 g, h$ ). This plateau might be caused by either the $\mathrm{Ca}^{2+}$ concentration being constant during this phase or by saturation of the indicator dye. To decide between these possibilities, we used the $\mathrm{Ca}^{2+}$ indicator Fluo5N that has a higher $K_{\mathrm{d}}(90 \mu \mathrm{M})$ than OG5N $(20 \mu \mathrm{M})$. The recordings with Fluo5N (Fig. 4a,b) clearly do not show a plateau. Furthermore, the fluorescence has declined after $500 \mathrm{msec}$ illumination to $10-20 \%$ of the peak value (relative to the initial level; Fig. $4 b, c$ ), being a much lower level than in the recordings with OG5N, where the fluorescence level after $500 \mathrm{msec}$ illumination still is $40-60 \%$ of the peak value (Fig. $4 e, f$ ). These observations are consistent with the lower $\mathrm{Ca}^{2+}$ affinity of Fluo5N with respect to OG5N and show that OG5N saturates during the initial peak.

From its $K_{\mathrm{d}}$ value of $20 \mu \mathrm{M}$, OG5N is expected to saturate at $\mathrm{Ca}^{2+}$ concentrations $>200 \mu \mathrm{M}$, whereas, given its $K_{\mathrm{d}}$ of $90 \mu \mathrm{M}$, Fluo5N should saturate at $\mathrm{Ca}^{2+}$ concentrations $>1 \mathrm{~mm}$. We therefore estimate that the $\mathrm{Ca}^{2+}$ concentration reached in the rhabdomeres of dark-adapted fly photoreceptor cells during the initial peak shortly after light onset is in the range between 0.2 and $1 \mathrm{~mm}$.

\section{Quantification of the free $\mathrm{Ca}^{2+}$ concentration in the rhabdomere}

We can convert the fluorescence traces obtained with OG5N into $\mathrm{Ca}^{2+}$ concentrations for fluorescence values that are not close to saturation at either end of the dynamic range of the indicator dye OG5N. The saturation of OG5N at the onset of the light stimulus can be used to obtain the maximum fluorescence signal $\left(F_{\max }\right)$. Because the resting free $\mathrm{Ca}^{2+}$ concentration in the photoreceptor cells is $<1 \mu \mathrm{M}$ (Hardie, 1996a; Oberwinkler and Stavenga, 1998), we can take the initial level of fluorescence (before the light-induced fluorescence increase, Figs. 2-4) as the minimum fluorescence, $F_{\text {min }}$. Using $F_{\text {max }}, F_{\text {min }}$, and the published $K_{\mathrm{d}}$ values of $20 \mu \mathrm{M}$ for OG5N (Haugland, 1996), we obtain the free $\mathrm{Ca}^{2+}$ concentration as described in Materials and Methods (Fig. 5e,f). It shows an enormous peak exceeding $200 \mu \mathrm{M}$ soon after the 


\section{chalky}
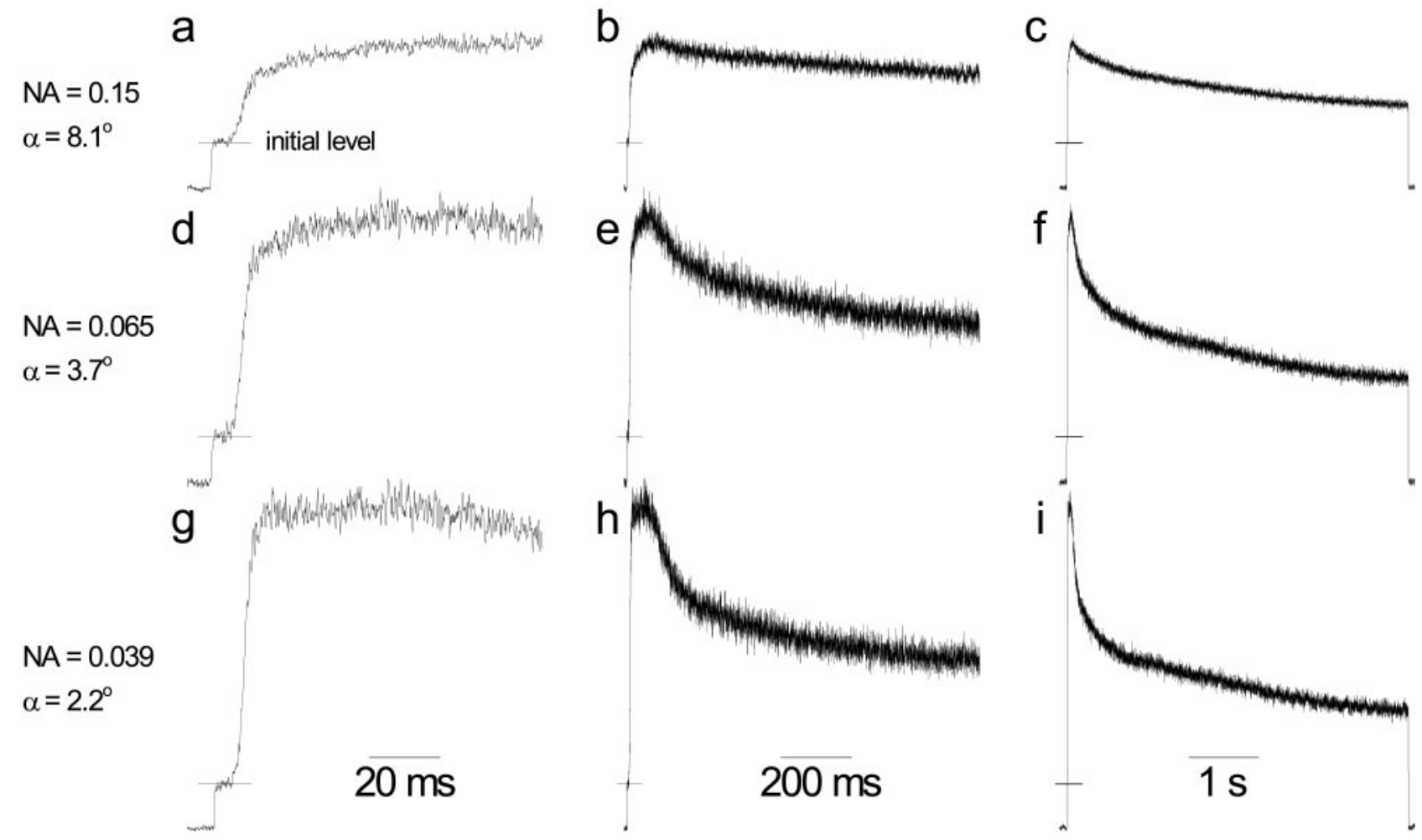

Figure 3. Effect of the NA of the objective on the fluorescence signal recorded from a chalky fly. The fluorescence signals from the $\mathrm{Ca}^{2+}$ indicator dye OG5N recorded with three different NAs (values as indicated in the figure) are shown; the data are shown on three different time scales. The traces shown for the three different NA have been normalized to the initial level of fluorescence (indicated by the small horizontal lines) to facilitate comparison between recordings. Reducing the NA of the objective increases the size and the speed of the initial transient. This shows that the kinetics and the concentrations of the free $\mathrm{Ca}^{2+}$ concentration inside the rhabdomere are different from that of the free $\mathrm{Ca}^{2+}$ concentration in the cell body. When using small NAs $(g-i)$, the recordings shown are very similar in the first $500 \mathrm{msec}$ to those obtained with wild-type flies (Fig. 2). In particular, the fast rise $\sim 5$ msec after the onset of light stimulation, the plateau at the highest fluorescence values, and the decrease to $\sim 50 \%$ fluorescence level (between the initial level and the peak) are highly similar to recordings from wild-type flies. This indicates that the isolation of the fluorescence from the rhabdomere in chalky flies is as good as in wild-type flies. The important advantage of using chalky flies is the absence of a pupil effect $(i)$.

beginning of the light stimulation that rapidly levels off to values between 10 and $30 \mu \mathrm{M}$ that are reached already $500 \mathrm{msec}$ after light onset (Fig. 5e). For longer illumination times, the free $\mathrm{Ca}^{2+}$ concentration continues to decay with a slow time constant (Fig. 5f).

Figure 6 shows the average of the free $\mathrm{Ca}^{2+}$ concentrations found after $500 \mathrm{msec}$ and $5 \mathrm{sec}$ of illumination for several experiments similar to the one shown in Figure 5. After $500 \mathrm{msec}$, both in wild-type flies and in chalky mutants the free $\mathrm{Ca}^{2+}$ concentration in the rhabdomere is $20 \mu \mathrm{M}(+/-5 \mu \mathrm{M} \mathrm{SD}$; min, $12 \mu \mathrm{M}$; $\max , 30 \mu \mathrm{M})$. These data can be used to further narrow the estimate for the $\mathrm{Ca}^{2+}$ concentration at the peak. We find that the fluorescence level in Fluo5N recordings after $500 \mathrm{msec}$ of illumination is $21 \%(+/-8 \% \mathrm{SD}, n=4)$ of the fluorescence level at the peak. Given a $K_{\mathrm{d}}$ of $90 \mu \mathrm{M}$ and assuming that, on average, also in the Fluo5N recordings $\left[\mathrm{Ca}^{2+}\right]_{\mathrm{rh}}$ after $500 \mathrm{msec}$ illumination is 20 $\mu \mathrm{M}$, the $\mathrm{Ca}^{2+}$ concentration at the peak can be estimated to reach $\sim 600 \mu \mathrm{M}$.

Because of the pupil mechanism, the $\mathrm{Ca}^{2+}$ concentration after $5 \mathrm{sec}$ illumination can only be determined for chalky flies. In the mutant flies, $\left[\mathrm{Ca}^{2+}\right]_{\mathrm{rh}}$ has declined to $8 \mu \mathrm{M}(+/-3 \mu \mathrm{M} \mathrm{SD}$; min, $6 \mu \mathrm{M}$; max, $11 \mu \mathrm{M}$ ) after $5 \mathrm{sec}$ illumination (Fig. 6). This shows that modulation of the light response has components that work on the time scale of seconds. Interestingly, the membrane potential changed only moderately (Fig. $5 b)$, declining from $51 \%(+/-$ $3 \% \mathrm{SD}$ ) of its peak value after $500 \mathrm{msec}$ light stimulation to $45 \%$ $(+/-4 \% \mathrm{SD})$ of the peak value after $5 \mathrm{sec}$ light stimulation.

\section{Light adaptation decreases the duration and the size of the $\mathrm{Ca}^{2+}$ transient}

In Figure 7 responses of a cell adapted to three different background intensities are shown, differing from each other by a logarithmic unit; OG5N was used as the fluorescent $\mathrm{Ca}^{2+}$ indicator. Light adaptation shortens the duration of the fluorescence transient at the onset of the light stimulus to $\sim 30 \mathrm{msec}$ (Fig. $7 d-f)$; in dark-adapted cells this transient lasts at least $100 \mathrm{msec}$ (Figs. 2-4). Comparing the different levels of light adaptation shows that the transient phase of both the fluorescence signal and the membrane potential are shortened when the background intensity is increased. Additionally, the size of the transient fluorescence peak is reduced when the cell is adapted to stronger background lights (Fig. 7, compare $d, f$ ). The initial transient of the membrane potential measured simultaneously with the fluorescence also shows a decrease in duration when the background intensity is increased (Fig. $7 a-c$ ). These observations are consistent with the notion that the increase in $\left[\mathrm{Ca}^{2+}\right]_{\mathrm{rh}}$ measured with 


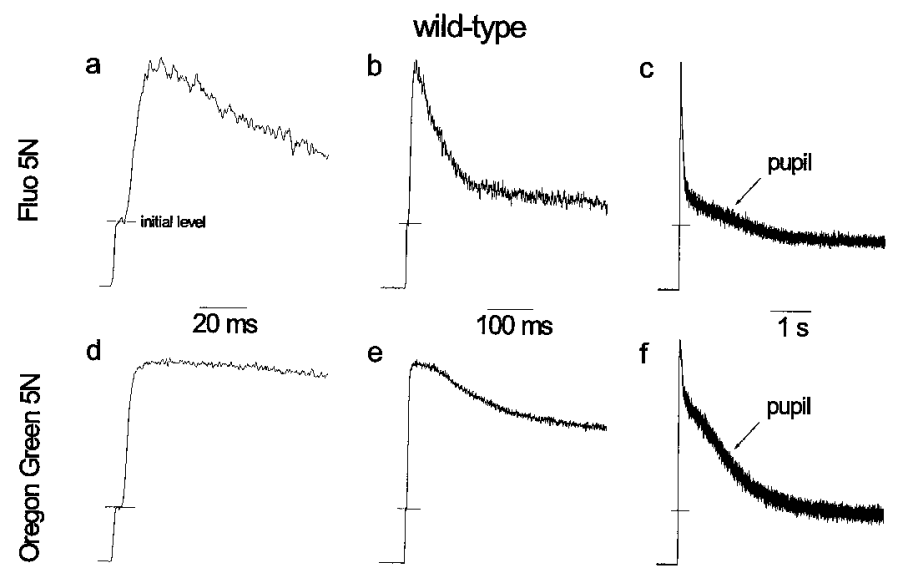

Figure 4. Comparison of fluorescence obtained with Fluo5N $(a-c)$ and OG5N ( $d-f$; traces are identical to Fig. 2 and are reproduced for better comparison). The two recordings are each shown on three different time scales. Although the recordings with OG5N show a flat plateau at their maximum value $(d, e)$, the recordings with Fluo5N show a sharp peak $(a$, $b)$. Furthermore, in the Fluo5N recordings, the fluorescence levels off to only $\sim 10 \%$ of the dynamic range, but the OG5N traces maintain a level of $\sim 50 \%$ (after $500 \mathrm{msec}$ ). Both these observations are consistent with the lower affinity of Fluo5N with respect to OG5N. Accordingly, the flat peak seen in the traces obtained with OG5N and not with Fluo5N should be interpreted as attributable to saturation of the OG5N dye. Consequently, the free $\mathrm{Ca}^{2+}$ concentration in the rhabdomere rises to levels between 200 and $1000 \mu \mathrm{M}$ during this plateau phase. Because these recordings were performed with wild-type flies, the pupil effect is visible at times longer than $0.5 \mathrm{sec}(c, f)$. The initial level of fluorescence is indicated by the small horizontal lines.

the low-affinity indicator OG5N is predominantly caused by $\mathrm{Ca}^{2+}$ entering through the light-activated channels (Hardie and Minke, 1992; Ranganathan et al., 1994; Peretz et al., 1994; Huber et al., 1996a; Niemeyer et al., 1996; Reuss et al., 1997).

In addition to its effect on the duration of the transients of membrane potential and fluorescence signal, light adapting a photoreceptor cell increases the free $\mathrm{Ca}^{2+}$ concentration throughout the cell (Oberwinkler and Stavenga, 1998). This can also be seen in Figure $7 d-f$, where the initial level of $\left[\mathrm{Ca}^{2+}\right]_{\mathrm{rh}}$ increases with increasing intensity of the adapting background (arrows).

\section{Quantification of the $\mathrm{Ca}^{2+}$ signal of light-adapted cells}

To quantify the free $\mathrm{Ca}^{2+}$ concentration in the rhabdomere of light-adapted cells, we have used a double pulse protocol (Fig. 8) for recording the responses. The rationale behind this procedure is to record the light-adapted response shortly after the darkadapted response. This reduces errors caused by bleaching or otherwise reduced concentration of the indicator dye as well as errors caused by changes in the health of the cell from which we recorded. In Figure 8 we exposed a dark-adapted cell to a 500 msec flash that was followed by a $200 \mathrm{msec}$ period of darkness followed by a second light stimulus. Figure $8 a$ shows that the second light stimulation evoked an electrical response with the reduced duration and size characteristic of light-adapted cells. From the simultaneously recorded fluorescence trace (Fig. 8b), we hence can calculate $\left[\mathrm{Ca}^{2+}\right]_{\mathrm{rh}}$ during the dark-adapted and the light-adapted light response (Fig. 8c), as outlined above (Fig. 5). Figure $8 c$ shows that $\left[\mathrm{Ca}^{2+}\right]_{\mathrm{rh}}$ reaches, as already found in Figure 5, values exceeding $200 \mu \mathrm{M}$ when the cells are dark-adapted. During the light-adapted response, however, the $\mathrm{Ca}^{2+}$ transient starts from $\sim 3 \mu \mathrm{M}$ to reach $50 \mu \mathrm{M}$ before it declines again.

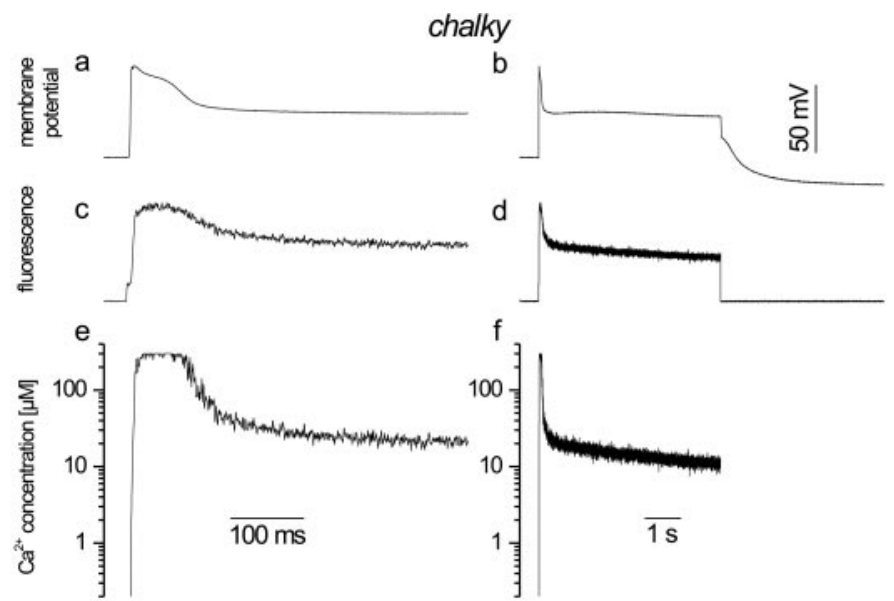

Figure 5. Membrane potential $(a, b)$, concomitantly measured OG5N fluorescence $(c, d)$, and calculated free $\mathrm{Ca}^{2+}$ concentrations in the rhabdomere $(e, f)$ during illumination of a dark-adapted photoreceptor cell. The data are displayed twice, at high temporal resolution $(a, c, e)$ and at lower temporal resolution $(b, d, f)$. The method used for calculating the free $\mathrm{Ca}^{2+}$ concentration from the fluorescence signal is explained in Results; note that only fluorescence values in the dynamic range of the $\mathrm{Ca}^{2+}$ indicator OG5N (representing free $\mathrm{Ca}^{2+}$ concentrations between 2 and $200 \mu \mathrm{M}$ ) can be converted into free $\mathrm{Ca}^{2+}$ concentrations. During the peak of the membrane potential, the free $\mathrm{Ca}^{2+}$ concentration in the rhabdomere exceeds this range; the free $\mathrm{Ca}^{2+}$ concentration in the rhabdomere during this short period can therefore not be determined, but must exceed $200 \mu \mathrm{M}$. From its peak, the free $\mathrm{Ca}^{2+}$ concentration in the rhabdomere reduces quickly to $20 \mu \mathrm{M}$ in $500 \mathrm{msec}(e)$. At longer illumination times, the free $\mathrm{Ca}^{2+}$ concentration slowly reduces further, in this cell to 11 $\mu \mathrm{M}$ after $5 \sec (f)$.

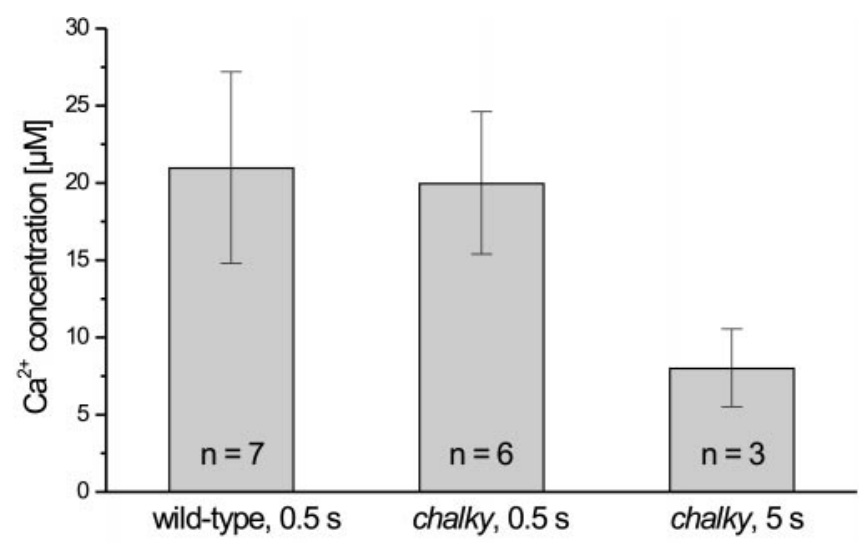

Figure 6. Summary of several experiments similar to the one shown in Figure 5. At $0.5 \mathrm{sec}$ after the onset of bright illumination, the free $\mathrm{Ca}^{2+}$ concentration in the rhabdomeres of wild-type and chalky flies is on average $20 \mu \mathrm{M}$. At $5 \mathrm{sec}$ after the onset of bright illumination, the free $\mathrm{Ca}^{2+}$ concentration has declined to $8 \mu \mathrm{M}$ in chalky flies. The pupil mechanism present in wild-type flies makes it impossible to obtain quantitative data for $\left[\mathrm{Ca}^{2+}\right]_{\mathrm{rh}}$ later than $0.5 \mathrm{sec}$ after the onset of the light stimulus. Error bars indicate SD.

Interestingly, physiologically important feedback regulations can be observed in this range of concentrations (Hardie, 1995).

\section{The membrane potential leads the $\mathrm{Ca}^{2+}$ signal in dark- and light-adapted cells}

Invertebrate photoreceptors possess $\mathrm{Ca}^{2+}$ stores located in close vicinity to the rhabdomeric membrane, the so-called subrhabdomeric cisternae, that are able to take up $\mathrm{Ca}^{2+}$ (Walz, 1982). In Drosophila, $\mathrm{Ca}^{2+}$ can be released from these stores by treating 

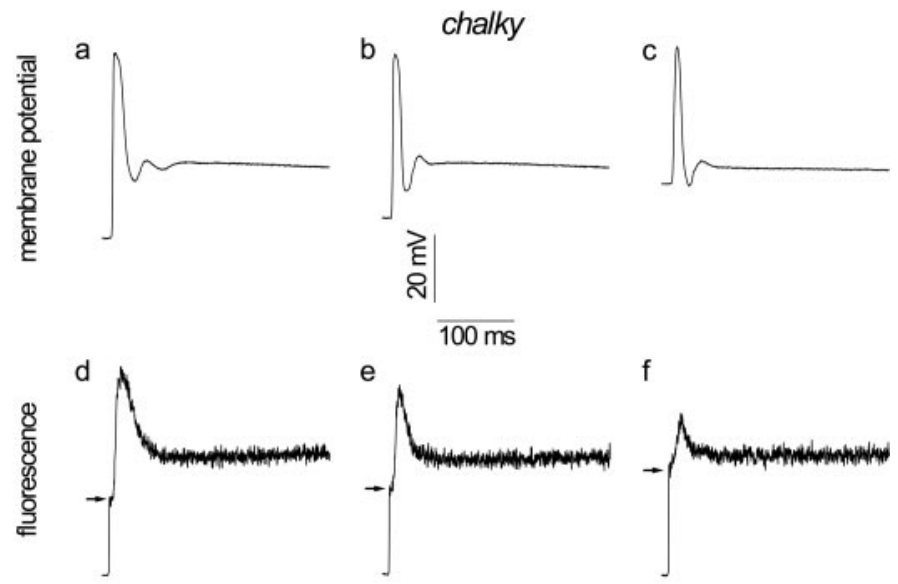

$$
\log 1=-3
$$

$\log 1=-2$
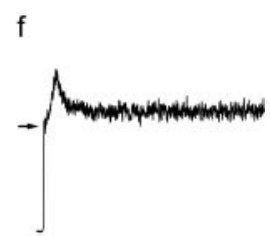

$\log \mid=-1$

Figure 7. Increasing the intensity of the adapting light reduces both the duration of the transient of the membrane potential and the duration and the size of the transient of the fluorescence signal at the onset of the light stimulation. The electrical response of a light-adapted chalky photoreceptor cell to a test stimulus $(a-c)$ and the accompanying fluorescence signal $(e-f)$ is shown. Three different intensities, each differing by a log unit, were used as adapting background light. Additional to the effect on the initial transients, increasing the light adaptation also increases the steadystate $\mathrm{Ca}^{2+}$ concentration (arrows) seen before the test stimulus-induced increase (e.g., Oberwinkler and Stavenga, 1998). The fluorescence was recorded with an increased NA, equivalent to a visual angle of $\sim 8^{\circ}$.
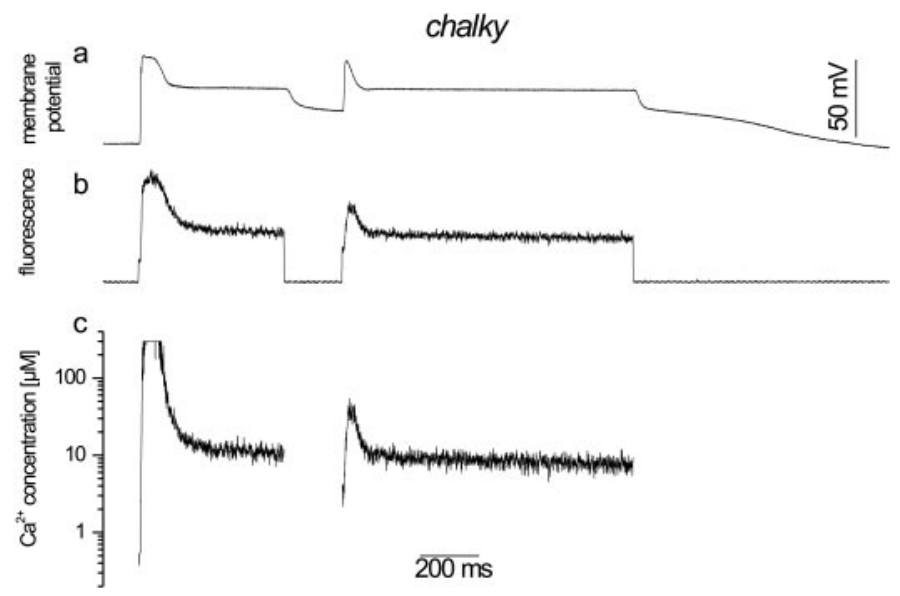

Figure 8. Quantification of the free $\mathrm{Ca}^{2+}$ concentration in the rhabdomere of light-adapted photoreceptor cells. Light adaptation was induced by a $500 \mathrm{msec}$ light stimulus onto a dark-adapted photoreceptor cell. This stimulus was followed by a dark interval lasting $200 \mathrm{msec}$ and a subsequent stimulus to record the light-adapted response. This protocol allows to directly compare the dark- and the light-adapted response and to calculate the free $\mathrm{Ca}^{2+}$ concentration in the rhabdomere $(c)$, as shown in Figure 5, from the OG5N fluorescence trace $(b)$. To avoid the pupil mechanism a chalky fly was used in this experiment. The traces show that the $\mathrm{Ca}^{2+}$ concentration reached in the rhabdomere exceeds $200 \mu \mathrm{M}$ in dark-adapted rhabdomeres, but changes between 3 and $50 \mu \mathrm{M}$ during the light-adapted response.

the cells with thapsigargin or ionomycin (Hardie, 1996b). For Drosophila, it is controversially debated if a $\mathrm{Ca}^{2+}$ release from stores also occurs as a consequence of light stimulation. Hardie (1996a) found that the free $\mathrm{Ca}^{2+}$ concentration in the cytosol increased by $20 \mathrm{~nm}$ at most when eliminating $\mathrm{Ca}^{2+}$ influx through the light-activated channels. Cook and Minke (1999), on the other hand, reported that excitability of the cells correlated with the

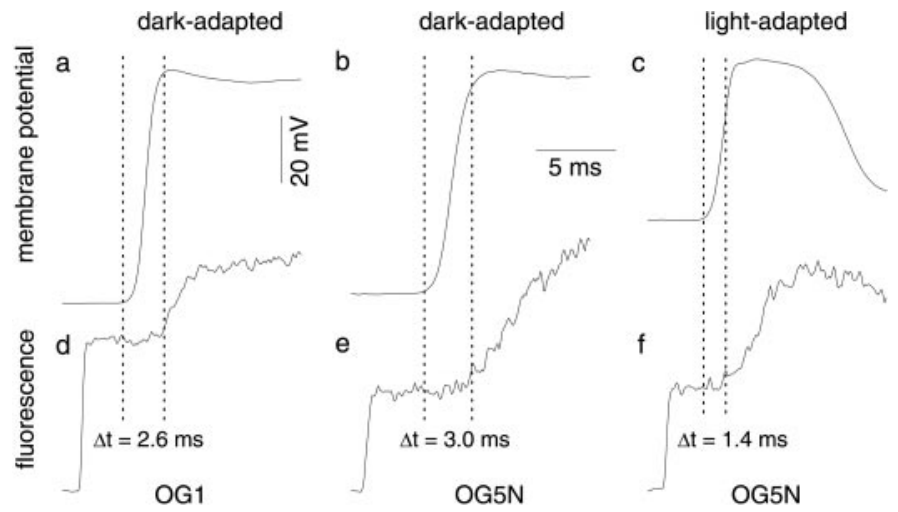

Figure 9. The first discernible changes of the membrane potential precede the first discernible changes of the fluorescence signal. The first noticeable changes have been determined as outlined in Results and are indicated as dotted lines. The leftmost dotted line in each panel indicates the end of the latency period of the membrane potential. In dark-adapted photoreceptor cells, the delay between the membrane potential and the fluorescence amounts to 2-3 msec, independent of the use of either high-affinity (OG1; $a, d)$ or low-affinity (OG5N; $b, e) \mathrm{Ca}^{2+}$ indicators, confirming earlier results in other insects (Walz et al., 1994; Hardie, 1996a). Wild-type flies were used for the experiments on dark-adapted photoreceptor cells $(a, b, d, e)$. Also in light-adapted cells the membrane potential rises earlier than the fluorescence signal $(c, f)$. This particular recording represents the shortest delay we measured. It was performed in a chalky mutant adapted to a steady-state background and is identical to the recordings of Figure 7, $b$ and $e$.

ability to release $\mathrm{Ca}^{2+}$ from the stores and argued that the release might increase the free $\mathrm{Ca}^{2+}$ concentration only locally. In Limulus, it could be demonstrated that $\mathrm{Ca}^{2+}$ is released before any electrical signal (Ukhanov and Payne, 1995), whereas this was found not to be the case in the honeybee drone (Walz et al., 1994) and Drosophila (Hardie, 1996a). We reinvestigated this question because in the in vivo preparation it is possible to confine the measurements to the rhabdomeres, where any light-induced $\mathrm{Ca}^{2+}$ release should be larger than in other regions. Furthermore, our preparation allows us to investigate this question also for light-adapted cells.

We determined the latencies for the membrane potential and the fluorescence trace by calculating the minimal and the maximal values during a $1 \mathrm{msec}$ period starting $1 \mathrm{msec}$ after the fluorescence trace had reached $50 \%$ of the initial level, i.e., $1 \mathrm{msec}$ after the shutter was half open. The value obtained by adding twice the difference between the minimal and the maximal value to the maximal value was taken as the threshold. The latencies, defined by the moment when the membrane potential or the fluorescence signal crossed the threshold, are indicated in Figure 9 by dotted lines. In Figure 9, the leftmost dotted line always indicates the latency of the membrane potential. Therefore, also in Calliphora, the electrical signal leads any detectable increase in $\left[\mathrm{Ca}^{2+}\right]_{\mathrm{rh}}$ (Fig. 9). The latencies observed with the high-affinity $\mathrm{Ca}^{2+}$ indicator OG1 (reported $K_{\mathrm{d}}, 0.16 \mu \mathrm{M}$; Haugland, 1996; Fig. $9 a, d)$ and the low-affinity $\mathrm{Ca}^{2+}$ indicator OG5N (reported $K_{\mathrm{d}}, 20$ $\mu \mathrm{M}$; Haugland, 1996; Fig. 9b,e) show no essential difference. $\left[\mathrm{Ca}^{2+}\right]_{\mathrm{rh}}$ at the initial level during the latency period is $0.16 \mu \mathrm{M}$ (Hardie, 1996a). Using this value we calculate that the criterion for determining the latency for the fluorescence signal in Figure $9 d$ corresponds to $0.04 \mu \mathrm{M}$. Although $0.04 \mu \mathrm{M}$ is an increase that potentially has physiological functions in many cell types, it corresponds to only a single additional free $\mathrm{Ca}^{2+}$ ion in the 
volume of 11 microvilli (taking a microvillus to be a cylinder of 1.5 $\mu \mathrm{m}$ length and $0.06 \mu \mathrm{m}$ diameter). This calculation shows that probably neither an insufficient signal-to-noise ratio nor an insufficient sensitivity of the $\mathrm{Ca}^{2+}$ indicator have hindered the detection of an early increase in $\left[\mathrm{Ca}^{2+}\right]_{\mathrm{rh}}$; it might also explain why we did not observe any difference in latency whether using high- or low-affinity indicators. In light-adapted photoreceptor cells (Fig. $9 c, f)$, we equally found that the depolarization of the membrane precedes any detectable increase in $\left[\mathrm{Ca}^{2+}\right]_{\mathrm{rh}}$. Figure $9 f$ shows the shortest latency observed; typically the delay between the earliest detectable depolarization and the earliest detectable increase in $\left[\mathrm{Ca}^{2+}\right]_{\mathrm{rh}}$ was 2-3 msec also in light-adapted cells.

\section{DISCUSSION}

In this report we demonstrate the feasibility of measuring, with high temporal resolution, the free $\mathrm{Ca}^{2+}$ concentration exclusively from a small cellular compartment of blowfly photoreceptor cells, the rhabdomere. This compartment is of special interest because it contains the phototransduction machinery including the $\mathrm{Ca}^{2+}$ permeable TRP and TRPL channels (Huber et al., 1996a; Niemeyer et al., 1996) that are activated by light stimulation. The $\mathrm{Ca}^{2+}$ signals in this compartment are of extraordinary size and speed. We find that the free $\mathrm{Ca}^{2+}$ concentrations exceed $200 \mu \mathrm{M}$ and possibly reach $600 \mu \mathrm{M}$ within $20 \mathrm{msec}$ after the beginning of light stimulation. These $\mathrm{Ca}^{2+}$ concentrations exceed by far the concentrations measured even in small compartments of other neurons (e.g., stereocilia of hair cells, Lumpkin and Hudspeth, 1998; spines of central neurons, Petrozzino et al., 1995). Even the concentrations measured in the rhabdomeric region of Limulus ventral photoreceptor cells, the only other invertebrate species where quantitative data are available, are smaller $(\sim 150 \mu \mathrm{M}$; Ukhanov and Payne, 1995). The concentrations we measured in rhabdomeres of fly photoreceptor cells more closely resemble the concentrations measured in microdomains in the immediate vicinity of clusters of $\mathrm{Ca}^{2+}$ channels (Llinás et al., 1992).

\section{Precise localization of the fluorescence signal}

The rhabdomere optically acts as a waveguide and therefore a part of the light, the so-called boundary wave, is transported outside the rhabdomere. Our measurements hence necessarily include fluorescence that originated outside the rhabdomere, i.e., from dye molecules in the cell soma. Possibly, therefore, the intended spatial localization was compromised. Light at the wavelengths of $\sim 470-490 \mathrm{~nm}$, which maximally excites the indicator dyes, is transported predominantly in the first mode and in this mode only a small fraction of the light actually travels outside of the rhabdomere (for review, see Snyder, 1979; van Hateren, 1989). Only the intracellular part of the boundary wave will excite indicator dyes, the rest of the boundary wave being at the extracellular side of the rhabdomere. Additionally, fluorescence excited outside the rhabdomere has a reduced probability to be trapped by the rhabdomeric waveguide. We therefore conclude that the contamination of the fluorescence signal measured from wild-type photoreceptor cells with fluorescence from outside the rhabdomere will be minor. In chalky photoreceptor cells it is conceivable that a more substantial fraction of the light comes from other parts of the cell than the rhabdomere because of scattering. However, the close resemblance of the traces obtained from wild-type and from chalky flies when using low NAs indicates that also in chalky a good isolation of the fluorescence signal from the rhabdomere is possible (Figs. 2, 3).

An independent argument supports the notion that the mea- sured fluorescence signals predominantly stem from inside the rhabdomeric microvilli. The extracellular $\mathrm{Ca}^{2+}$ concentration in the fly retina is $1.4 \mathrm{~mm}$ (Sandler and Kirschfeld, 1991). Our measurements indicate that $\left[\mathrm{Ca}^{2+}\right]_{\mathrm{rh}}$ reaches values as high as $700 \mu \mathrm{M}$. The reversal potential for $\mathrm{Ca}^{2+}$,

$$
E_{\mathrm{rev}}=\frac{R T}{z F} \ln \left(\frac{\left[\mathrm{Ca}^{2+}\right]_{\mathrm{o}}}{\left[\mathrm{Ca}^{2+}\right]_{\mathrm{i}}}\right),
$$

then works out to be $+11 \mathrm{mV}$, which is very close to the reversal potential of the light-induced current in Drosophila (Reuss et al., 1997). It is also close to the peak values we measure for the membrane potential, as in good recordings we measured depolarizations of $70 \mathrm{mV}$ (Fig. 9a), and the resting potential of Calliphora photoreceptors is close to $-60 \mathrm{mV}$. During the initial transients elicited by strong illumination of dark-adapted photoreceptor cells, the $\mathrm{Ca}^{2+}$ gradient therefore is strongly reduced, and our estimates for the peak values of $\left[\mathrm{Ca}^{2+}\right]_{\mathrm{rh}}$ might approach the maximum value attainable given the strongly depolarized membrane. Therefore, it seems likely that the estimated values for $\left[\mathrm{Ca}^{2+}\right]_{\mathrm{rh}}$ reflect the free $\mathrm{Ca}^{2+}$ concentration inside the microvilli. These considerations can also explain why the peak values of $\left[\mathrm{Ca}^{2+}\right]_{\mathrm{rh}}$ are smaller than the estimates by Postma et al. (1999) who calculated that $\mathrm{Ca}^{2+}$ concentration changes in the millimolar range might occur in the rhabdomeric microvilli, when the membrane potential is clamped to $-70 \mathrm{mV}$. Furthermore, the close correspondence of the calculated reversal potential for $\mathrm{Ca}^{2+}$ ions and the membrane potential can be taken as an indication that the $K_{\mathrm{d}}$ of our $\mathrm{Ca}^{2+}$ indicators was not changed considerably by the intracellular environment. The $K_{\mathrm{d}}$ of $\mathrm{Ca}^{2+}$ indicators typically is shifted to larger values when used intracellularly as compared to an aqueous solution (Haugland, 1996; for invertebrate photoreceptors, Ukhanov et al., 1995; Hardie, 1996a). As the estimated values for $\left[\mathrm{Ca}^{2+}\right]_{\mathrm{rh}}$ are linearly related with the $K_{\mathrm{d}}$ of the indicator, a threefold to fivefold increase in $K_{\mathrm{d}}$ (Ukhanov et al., 1995; Hardie, 1996a) would also increase the estimated values $\left[\mathrm{Ca}^{2+}\right]_{\mathrm{rh}}$ by the same factor. This, however, would be inconsistent with the measured membrane potentials.

Our results confirm earlier reports on insect photoreceptors (Walz et al., 1994; Hardie, 1996a) that a period of 2-3 msec lies between the first discernible change of the membrane potential and that of the cytosolic free $\mathrm{Ca}^{2+}$ concentration. This seems to be independent of the use of low- or high-affinity indicators (Fig. 9). Because $>50 \%$ of the light-induced current is carried by $\mathrm{Ca}^{2+}$ ions (Hardie and Minke, 1992; Reuss et al., 1997; Postma et al., 1999), such a delay is counterintuitive because the influx of cations through light-activated channels should cause a simultaneous change in both the electrical signal and $\left[\mathrm{Ca}^{2+}\right]_{\mathrm{rh}}$. By limiting the origin of the fluorescence signal to the rhabdomere, we could provide evidence that our signal-to-noise ratio should be sufficient to detect early rises in $\left[\mathrm{Ca}^{2+}\right]_{\mathrm{rh}}$. To resolve this discrepancy, one might argue that the $\mathrm{Ca}^{2+}$ indicators cannot come close to the $\mathrm{Ca}^{2+}$ channels. However, $\mathrm{Ca}^{2+}$ released from photolabile $\mathrm{Ca}^{2+}$ buffers, molecules of sizes similar to the sizes of fluorescent $\mathrm{Ca}^{2+}$ indicators, affects the phototransduction within $1 \mathrm{msec}$ (Hardie, 1995). An alternative, not mutually exclusive, explanation is that endogenous $\mathrm{Ca}^{2+}$-binding proteins are present in the close vicinity of the light-activated channels that instantly bind all of the incoming $\mathrm{Ca}^{2+}$ during the first $2-3 \mathrm{msec}$ of the light response. Calmodulin might be a good candidate for such a $\mathrm{Ca}^{2+}$-binding protein, because it is present in high concentration in Drosophila rhabdomeres (Porter et al., 1993) and binds to 
several proteins that are thought to participate in a macromolecular assembly containing the light-activated channels (Huber et al., 1996a; Chevesich et al., 1997; for review, see Montell, 1998).

\section{Regulation of the membrane potential by $\mathrm{Ca}^{2+}$ in fly photoreceptors}

An increase in the $\mathrm{Ca}^{2+}$ concentration rapidly inhibits the light response in light-adapted photoreceptors (Hardie, 1995). Hardie (1995) also showed that increasing the free $\mathrm{Ca}^{2+}$ concentration in the range between 1 and $20 \mu \mathrm{M}$ strongly inhibits the light response. The observed changes in $\left[\mathrm{Ca}^{2+}\right]_{\mathrm{rh}}$ are in this range or exceed it in both light- and dark-adapted cells (Fig. 8), and are therefore well suited to convey physiologically important feedback signals. In particular, the transients in $\left[\mathrm{Ca}^{2+}\right]_{\mathrm{rh}}$ might be important in providing the feedback signal for the fast peak-toplateau transitions seen in the membrane potential, because those transitions are severely reduced when an increase of the free $\mathrm{Ca}^{2+}$ concentration is blocked by loading the cells with $\mathrm{Ca}^{2+}$ buffers (Muijser, 1979). Interestingly however, after light adaptation the size of the $\mathrm{Ca}^{2+}$ transients in the rhabdomere is reduced, but the speed of the peak-plateau transition of the membrane potential is increased (Figs. 7, 8). Considering that the $\mathrm{Ca}^{2+}$ transients provide the feedback signal for the membrane potential, these findings seem paradoxical. A possible explanation is that photoreceptor cells can react faster or with higher affinity to the feedback signal from the $\mathrm{Ca}^{2+}$ transients when they are light-adapted. The measurements of Figure 7 suggest that the increase in speed of the feedback or in its sensitivity for $\mathrm{Ca}^{2+}$ is graded with the intensity of the adapting light. In this scenario, an extension of the findings of Hardie (1995), the level of light adaptation defines the way and/or the speed the cells react to an increase in $\left[\mathrm{Ca}^{2+}\right]_{\mathrm{rh}}$.

Additionally to the fast events at the beginning of light stimulation we observed that $\left[\mathrm{Ca}^{2+}\right]_{\mathrm{rh}}$ continues to decline in the time range of seconds, at least up to $5 \mathrm{sec}$ after the onset of light stimulation (Figs. 5, 6). This was an unexpected finding, because the membrane potential, which is indicative of the $\mathrm{Ca}^{2+}$ influx through the light-activated channels, seemed to be rather stable during this period. This suggests that additional regulatory mechanisms exist in the photoreceptor cells that work relatively slowly, i.e., in the range of seconds.

\section{REFERENCES}

Bader CR, Baumann F, Bertrand D (1976) Role of intracellular calcium and sodium in light adaptation in the retina of the honeybee drone (Apis mellifera, L). J Gen Physiol 67:475-491.

Cook B, Minke B (1999) TRP and calcium stores in Drosophila phototransduction. Cell Calcium 25:161-171.

Chevesich J, Kreuz AJ, Montell C (1997) Requirement for the PDZ domain protein, INAD, for localization of the TRP store-operated channel to a signaling complex. Neuron 18:95-105.

Franceschini N, Kirschfeld K (1971) Les phénomènes de pseudopupille dans l'œil composé de Drosophila. Kybernetik 9:159-182.

Grynkiewicz G, Poenie M, Tsien RY (1985) A new generation of $\mathrm{Ca}^{2+}$ indicators with greatly improved fluorescence properties. J Biol Chem 260:3440-3450.

Hardie RC (1985) Functional organization of the fly retina. In: Progress in sensory physiology, Vol 5 (Ottoson D, ed), pp 1-79. Berlin: Springer.

Hardie RC (1995) Photolysis of caged $\mathrm{Ca}^{2+}$ facilitates and inactivates but does not directly excite light-sensitive channels in Drosophila photoreceptors. J Neurosci 15:889-902.

Hardie RC (1996a) INDO-1 measurements of absolute resting and lightinduced $\mathrm{Ca}^{2+}$ concentration in Drosophila photoreceptors. J Neurosci 16:2924-2933.

Hardie RC (1996b) Excitation of Drosophila photoreceptors by BAPTA and ionomycin: evidence for capacitative $\mathrm{Ca}^{2+}$ entry? Cell Calcium 20:315-327.
Hardie RC, Minke B (1992) The trp gene is essential for a light-activated $\mathrm{Ca}^{2+}$ channel in Drosophila photoreceptors. Neuron 8:643-651.

Hardie RC, Minke B (1994) Calcium-dependent inactivation of lightsensitive channels in Drosophila photoreceptors. J Gen Physiol 103:409-427.

Hardie RC, Minke B (1995) Phosphoinositide-mediated phototransduction in Drosophila photoreceptors: the role of $\mathrm{Ca}^{2+}$ and trp. Cell Calcium 18:256-274.

Hardie RC, Peretz A, Suss-Toby E, Rom-Glas A, Bishop SA, Selinger Z, Minke B (1993) Protein kinase C is required for light adaptation in Drosophila photoreceptors. Nature 363:634-637.

Haugland RP (1996) Handbook of fluorescent probes and research chemicals, Ed 6. Eugene, OR: Molecular Probes.

Howard J, Blakeslee B, Laughlin SB (1987) The intracellular pupil mechanism and photoreceptor signal:noise ratios in the fly Lucilia cuprina. Proc R Soc Lond B Biol Sci 231:415-435.

Huber A, Sander P, Gobert A, Bähner M, Hermann R, Paulsen R (1996a) The transient receptor potential protein (Trp), a putative store-operated $\mathrm{Ca}^{2+}$ channel essential for phosphoinositide-mediated photoreception, forms a signaling complex with NorpA, InaC and InaD. EMBO J 15:7036-7045.

Huber A, Sander P, Paulsen R (1996b) Phosphorylation of the InaD gene product, a photoreceptor membrane protein required for recovery of visual excitation. J Biol Chem 271:11710-11717.

Huber A, Sander P, Bähner M, Paulsen R (1998) The TRP Ca ${ }^{2+}$ channel assembled in a signaling complex by the PDZ domain protein INAD is phosphorylated through the interaction with protein kinase $\mathrm{C}$ (ePKC). FEBS Lett 425:317-322.

Kirschfeld K, Franceschini N (1969) Ein Mechanismus zur Steuerung des Lichtflusses in den Rhabdomeren des Komplexauges von Musca. Kybernetik 6:13-22.

Laughlin SB (1989) The role of sensory adaptation in the retina. J Exp Biol 146:39-62.

Lisman JE, Brown JE (1975) Effects of intracellular injection of calcium buffers on light adaptation in Limulus ventral photoreceptors. J Gen Physiol 66:489-506.

Llinás R, Sugimori M, Silver RB (1992) Microdomains of high calcium concentration in a presynaptic terminal. Science 256:677-679.

Lumpkin EA, Hudspeth AJ (1998) Regulation of free $\mathrm{Ca}^{2+}$ concentration in hair-cell stereocilia. J Neurosci 18:6300-6318.

Montell C (1998) TRP trapped in fly signaling web. Curr Opin Neurobiol 8:389-397.

Muijser H (1979) The receptor potential of retinular cells of the blowfly Calliphora: the role of sodium, potassium and calcium ions. J Comp Physiol 132:87-95.

Niemeyer BA, Suzuki E, Scott K, Jalink K, Zuker CS (1996) The Drosophila light-activated conductance is composed of the two channels TRP and TRPL. Cell 85:651-659.

Oberwinkler J, Stavenga DG (1998) Light dependence of calcium and membrane potential measured in blowfly photoreceptors in vivo. J Gen Physiol 112:113-124.

Obukhov AG, Schultz G, Lückhoff A (1998) Regulation of heterologously expressed transient receptor potential-like channels by calcium ions. Neuroscience 85:487-495.

Peretz A, Suss-Toby E, Rom-Glas A, Arnon A, Payne R, Minke B (1994) The light response of Drosophila photoreceptors is accompanied by an increase in cellular calcium: effects of specific mutations. Neuron 12:1257-1267.

Petrozzino JJ, Pozzo Miller LD, Connor JA (1995) Micromolar Ca ${ }^{2+}$ transients in dendritic spines of hippocampal pyramidal neurons in brain slice. Neuron 14:1223-1231.

Phillips AM, Bull A, Kelly LE (1992) Identification of a Drosophila gene encoding a calmodulin-binding protein with homology to the trp phototransduction gene. Neuron 8:631-642.

Porter JA, Yu M, Doberstein SK, Pollard TD, Montell C (1993) Dependence of calmodulin localization in the retina on the NINAC unconventional myosin. Science 262:1038-1042.

Postma M, Oberwinkler J, Stavenga DG (1999) Does $\mathrm{Ca}^{2+}$ reach millimolar concentrations after single photon absorption in Drosophila photoreceptor microvilli? Biophys J 77:1811-1823.

Ranganathan R, Harris GL, Stevens CF, Zuker CS (1991) A Drosophila mutant defective in extracellular calcium-dependent photoreceptor deactivation and rapid desensitization. Nature 354:230-232.

Ranganathan R, Bacskai BJ, Tsien RY, Zuker CS (1994) Cytosolic 
calcium transients: spatial localization and role in Drosophila photoreceptor cell function. Neuron 13:837-848.

Reuss H, Mojet MH, Chyb S, Hardie RC (1997) In vivo analysis of the Drosophila light-sensitive channels, TRP and TRPL. Neuron 19: 1249-1259.

Running Deer JL, Hurley JB, Yarfitz SL (1995) G protein control of Drosophila photoreceptor phospholipase C. J Biol Chem 270:12623-12628.

Sandler C, Kirschfeld K (1991) Light-induced extracellular calcium and sodium concentration changes in the retina of Calliphora: involvement in the mechanism of light adaptation. J Comp Physiol [A] 169:299-311.

Scott K, Sun Y, Beckingham K, Zuker CS (1997) Calmodulin regulation of Drosophila light-activated channels and receptor function mediates termination of the light response in vivo. Cell 91:375-383.

Snyder AW (1979) The physics of vision in compound eyes. In: Handbook of sensory physiology, Vol. VII/6A (Autrum H, ed), pp 225-313. Berlin, Heidelberg: Springer.

Stavenga DG (1983) Fluorescence of blowfly metarhodopsin. Biophys Struct Mech 9:309-317.

Ukhanov K, Payne R (1995) Light activated calcium release in Limulus ventral photoreceptors as revealed by laser confocal microscopy. Cell Calcium 18:301-313.

Ukhanov KY, Flores TM, Hsiao HS, Mohapatra P, Pitts CH, Payne R (1995) Measurement of cytosolic $\mathrm{Ca}^{2+}$ concentration in Limulus ventral photoreceptors using fluorescent dyes. J Gen Physiol 105:95-116.

van Hateren JH (1984) Waveguide theory applied to optically measured angular sensitivities of fly photoreceptors. J Comp Physiol [A] 154: $761-771$.

van Hateren JH (1989) Photoreceptor optics, theory and practice. In: Facets of vision (Stavenga DG, Hardie RC, eds), pp 74-89. Berlin, Heidelberg: Springer.

Walz B (1982) Calcium-sequestering smooth endoplasmic reticulum in retinula cells of the blowfly. J Ultrastruct Res 81:240-248.

Walz B, Zimmermann B, Seidl S (1994) Intracellular $\mathrm{Ca}^{2+}$ concentration and latency of light-induced $\mathrm{Ca}^{2+}$ changes in photoreceptors of the honey bee drone. J Comp Physiol [A] 174:421-431.

Warr CG, Kelly LE (1996) Identification and characterization of two distinct calmodulin-binding sites in the Trpl ion-channel protein of Drosophila melanogaster. Biochem J 314:497-503. 